when it was decided to again open the Library, during the winter season, on Sundays. MARK H. JUDGE, Honorary Secretary of the Sunday Society 8, Park Place Villas, Paddington, W., November I 7

\section{A Pugnacious Frog}

A shok't time back, about 6 o'clock in the evening, just as it was getting dark, hearing a squeaking noise below my veranda, I got up to look, and saw a most amusing sight, viz. a fight between a frog and a bat. The latter was evidently getting the worst of it, but at last suceeeded in getting away for a time from its opponent; the frog again attacked it, but this time he was glad to cry "quits," as the bat turned on him and beat him off, afterwards managing to hide somewhere so that we could not find it ; the frog, however, was sorely bitten about the nose, and was in a sad plight. I do not know how the bat could have been on the ground, but it had probably fallen from its nest during the day, and was waiting for the evening, when the frog espied and attacked it with the bef re-mentioned result.

Margapala, Soemedang, Java, October 13 EDWIN H. Evans

\section{A DISEASE-GERM MYTH}

$\mathrm{W}^{\mathrm{E}}$

$\mathrm{E}$ are indebted to a correspondent for the following curious note from $\mathrm{Fiji}$ :-

You may have seen Wilfred Powell's "Wanderings in a Wild Country; or, Three Years among the Cannibals of New Britain." If you have not seen it, pray send for it, for, though falling far short of what it ought to be, it is not without interest. At p. 167 he tells a story of native magic which reminds me of something I have read before.

A native doctor being called in to a patient "looking wretchedly ill," performs a little "devil-devil " business, and then blows some burnt lime from the hollow of his hand against the patient's stomach; "then he began to scratch the man's navel with one finger," gradually approaching his mouth to the fellow's stomach, and drawing in his breath. Presently he places his mouth close to the man's navel, draws back suddenly, retches violently, and-throws up a worm. This the worthy doctor does twice.

Powell says, "I looked at the worms, they were unlike anything $I$ had seen before, and appeared as if they certainly might have come from a man's body."

Now see Bates on the Amazons, cap. ix. :- "This (the illness) the Pagá pretends to extract, he blows on the seat of pain the smoke from a large cigar, . . and then sucks the place, drawing from his mouth, when he has finished, what he pretends to be a worm. . . . Senhor John contrived to get possession of the supposed worm after the trick was performed in our presence, and it turned out to be a long white air root of some plant"!!

Wilfred Powell should have got that worm or another specimen, even if he had been compelled, in the interests of science, to explore the patient's stomach with a pickaxe.

When Macdonald, of the old surveying-ship Herald, was in these waters, he was daily searching for a specimen of the pearly Nautilus ( $N$. pompilius), which is pretty common here. One day upon the reef at Nasamusovu he met a Fijian coming out of his canoe in which he had been fishing. He showed him the picture of a Nautilus, which the man recognised at once, and, in reply to a question put through an interpreter, said he had just eaten one. Macdonald got into a great rage at the loss of such a treasure, but suddenly checking his excitement and glancing rapidly over the native, he said to the interpreter, "Quick, ask him how long it is since he ate it."

But there was something in the eye and the tone of the doctor's voice that so startled the gentle child of Nature that, before the interpreter could open his mouth, he had taken to his heels and put half a mile of reef between himself and the man of science.

What awful thought passed through Macdonald's mind has not been left on record.

\section{THE BUDDHIST THEORY OF EVOLUTION}

$\mathrm{THE}$ theory of evolution held by adepts in Buddhism is the outcome of the researches of an immense succession of investigators, believed to be qualified for their task by the possession of spiritual faculties and perceptions of a higher order than those belonging to ordinary humanity. In the course of ages the block of knowledge thus accumulated concerning the origin of the world and of man and the ultimate destinies of our race, checked and examined at every point, verified in all directions, and constantly under examination throughout, has come to be looked on as the absolute truth concerning the evolution, past and to come, of man and the planets he is destined to inhabit. The initiated members or "adepts" of the Buddhist cult claim to have attained, through intense self-absorption, a knowledge of physical laws of Nature not yet understood by Western science, investing them with extraordinary powers known as spiritualistic, such as clairvoyance and the disintegration and reconstruction of matter by a simple effort of will. They claim in fact to be in possession of potential faculties which will only be generally developed in future stages of evolution. This religion, which is wholly unaggressive and seeks no converts, attracts many on account of its claims to be in accord with all established scientific fact, and by its incorporation of so patent a truth as the doctrine of evolution as an integral part of its system.

A brief examination of these claims, and a glance at the past and future of man's evolution as thus elaborated, can hardly fail to be of interest, if it fails to carry conviction.

It is impossible, and unnecessary, to attempt to follow briefly the mystic subtleties of belief that have fascinated the Oriental mind, and been to it for ages what the pursuit of practical science has been to Western nations. Shortly stated, the Buddhist divides the human entity into seven principles, the higher of which have not yet reached their full development. The first three are of the earth, and done with at death. These are (I) the body ; (2) vitality, or the life principle, an indestructible force which attaches itself to other objects after the decomposition of the body ; (3) the astral body, "an ethereal duplicate of the physical body," which can under certain circumstances become disembodied and visible as a ghost ; (4) the animal soul, or seat of all animal desires ; (5) the human soul. The other two can be passed over, as they are still in embryo, and belong to a wholly superior and future condition of existence. The fifth and, later on, the sixth principles make up a man's continuous individuality through successive incarnations.

The solar system consists of seven planetary chains. The one with which man is concerned consists of seven planets, through each of which he has to pass seven times in order to accomplish his evolution. These are the Earth, Mars, which is in a state of entire obscuration or rest as regards the human life-wave, Mercury, just beginning to prepare for its next human period, and four other planets which are composed of an order of matter too ethereal for telescopes to take cognisance of. The system of worlds is compared to a system of towers standing on a plain, each of many stories, man's progress being a spiral round and round the series, passing through each tower as it again comes round to it, at a higher spiritual level than before. The impulse to the new evolution of higher forms is given by rushes, not a continual flow, of spiritual monads coming round the cycle in a state fit for the inhabitation of new forms, and those which for milleniums have gone on merely 
repeating themselves then start afresh into growth, and rise rapidly, through intermediate, to the higher forms. The spiral character of the progress, and the fact that the tide of life passes from planet to planet in gushes, accounts for the gaps in the various kingdoms of Nature. Each time a spiritual monad arrives on a planet it has a complicated process of evolution to perform. It is many times incarnated before it passes onward, and man has many incarnations in each great race, the normal sum being not far short of 800 , with an interval of at least 1500 years between each, spent in the "world of effects, or heaven of ordinary theology." In the first planetary round man inhabited an immense but loosely organised body, and could not be called intellertual. In the second he becomes of firmer body, whilst in the third he is rather in form of a giant ape than true man, yet of concrete body and advanced intelligence. In the fourth, the present round, his intellect becomes fully developed, and he achieves enormous progress. We now approach the transcendental mystery of mysteries, our future development. The fifth round will be occupied with a struggle between physical intellect and spirituality. In the sixth round a state of perfection of body and soul will be attained which can hardly even be imagined; while as to the seventh round the occult teachers themselves are solemnly silent, it being altogether too God-like for realisation. At the end of each planetary round an intercyclic period of extraordinary exaltation must be undergone. It is by processes of occult training that adepts project themselves precociously into the fifth round, or possess themselves of the attributes of fifth-round men, so as to be able to explore the mysteries of Nature and of other states of existence, and to assimilate knowledge by clairvoyance independently of observation.

We now exist in the fifth race of the fourth round. The first and second races developed no civilisation, but the third and fourth did do so several millions of years ago, though no traces of such now exist. The periods of the great root races are divided by vast convulsions or geological changes, which cut them off at the appointed time, leaving only a few survivors behind, who rapidly relapse into barbarism. The fourth race lived on "Atlantis," and reached its apogee in "the Eocene Age," when this great continent showed the first symptoms of sinking, a process that occupied it down to II, 446 years ago, when its last island, Poseidonis, went down with a crash. "Lemuria" was drowned with its high civilisation and gods about 700,000 years earlier than Atlantis, or just before the early part of the Eocene Age, the relics of its third-race inhabitants existing in some of the flat-headed aborigines of Australia. The true Chinaman is interesting as a relic of the fourth race. The civilisations of the ante-Glacial period were superior to those of Greece and Rome, or the Egyptian, which was in its decadence 12,000 years ago. The uninhabited Arctic regions will prove not only to have enjoyed a tropical climate, but were likewise the seat of one of the most ancient civilisations of the fourth race. Atlantis belonged to the Miocene times, and the cataclysm which destroyed it came at the appointed time, "otherwise it would be impossible for the best seer to calculate the exact hour and year when such cataclysms great and small have to occur." The relics of these former civilisations are hidden in strata which have never been geologically explored, deep in the unfathomed ocean beds.

An important part of the Buddhist creed is the belief in the alternation of periods of repose with periods of activity. As man sleeps every twenty-four hours, and vegetation subsides and revives with the seasons, so rest periods follow each incarnation. The tide-wave of humanity flows on to each of the seven planets seven times, and passes through its seven races and ebbs away again, but the great rest period of our planetary chain does not begin until the seventh round of humanity is perfected. At an incalculably remote period the whole of the seven planetary chains of our solar system will pass into a period of rest, and finally the whole universe itself will have its great cosmic night. After the long night of a planetary chain the animal and vegetable world resume their arrested activity, but when the time arrives for all the planetary chains of our system to pass into their night, each planet, as the seventh-round man quits it, is annihilated instead of merely becoming invisible, and there is an outflow from every kingdom of its entities. These will rest in lethargic sleep in space until brought into life again at the next solar period, and will then form the soul of the future globe. We have every indication that at this very moment such a solar night is taking place, while there are two minor ones ending somewhere. At the beginning of the next solar day period the hitherto subjective elements of the material worlds, now scattered in cosmic dust, will form into primordial ripples of life, and, separating into differentiating centres of activity, combine in a graduated scale of seven stages of evolution. Every orb will pass through seven stages of density, until its solidification and desiccation at last reach a point when it becomes a relaxed conglomerate, and its constituent masses cease to obey the laws of cohesion which hold them together.

Evolution takes its rise in the atomic polarity which motion engenders. In cosmogony the active and passive forces correspond to the male and female principles. The attribute of the universal spiritual principle is to expand and shed, of the material principle to gather and fecundate. These become consciousness and life when brought together. Our planet, like an iceberg, is merely a state of being for a given time, and its present appearance, geological and anthropological, is but transitory and will pass away.

Such are the beliefs and doctrines concerning evolution ${ }^{1}$ held by the Oriental scholar, who holds in pity the benighted ignorance of Western so-called science. The book from which they are gathered is sober earnest, and I am asked whether the Buddhist ideas on evolution are in accord with the discoveries of science. The mere statement of the belief, shorn of its mysticism, is a sufficient answer. The importance attached to the numeral ? seems puerile, and its reason is not easy to discover; it is claimed that the colours of the spectrum and the notes of the musical scale are seven, and that there are seven kingdoms in Nature. There is one seeming scientific fact, however, which, though it has escaped the "adepts," favours so far the belief in evolution by gushes, and is still unexplained. The first appearance of many forms of life on our planet, it is well known, is very sudden. All the groups of Mollusca, and especially in the case of Ammonites, appear at once fully developed and in great variety of species, and never develop into anything higher. So with the Echinodermata, the Crustacea, Insecta, the different orders of fishes, many orders of reptiles, marsupials, ferns, and dicotyledons. All these seem to have been evolutionised in a very sudden manner, and as yet afford no grounds for controverting the Buddhist belief that they are well developed arrivals from other planets.

\section{J. Starkie Gardner}

\section{THE RAINFALL OF 1884}

THE water famine with which the towns of Manchester and Bradford have recently been threatened has served to draw public attention to the fact that the rainfall of the present year has been strikingly deficient. As the extent of the deficiency is, however, little, or at the best imperfectly, realised, a few reliable statistics on the subject may be of more than ordinary interest.

The following table shows, for seventeen places situated

2 Condensed from Mr. A. P. Sinnett's book, "Esoteric Buddhism" (Trübner and (o.), and as far as possible in his own words. 